\title{
Passive design strategies for residential buildings in a hot dry climate in Nigeria
}

\author{
O. K. Akande \\ Architecture Programme, Abubakar Tafawa Balewa University, Nigeria
}

\begin{abstract}
The hot dry climatic zone of Nigeria is characterized by a period of high temperature and low relative humidity between February and May. Between these months, the daily mean maximum indoor temperature of most buildings is about $37^{\circ} \mathrm{C}$ with low indoor air velocity. A study of residential buildings in Bauchi state, Nigeria shows that most occupants of the buildings have persistent and growing problems with the indoor environment due to high indoor temperature. Most buildings are characterized by poor design in relation to the climate, which requires a great deal of energy for cooling during climatic extremes. Other problems are poor natural ventilation, inadequate surfacevolume ratio and poor building orientation. This has led to negative consequence that affect the occupant's physiological comfort, capacity for mental and physical work, health and leisure. This paper identifies passive design strategies that can be adopted in this climatic region to minimize the use of energy for cooling, improve occupant's comfort and enhance low energy architecture. The objective is to reduce overdependence on electricity demand and energy use in residential buildings. The result of the study shows that adopting certain passive design strategies through appropriate selection of building materials, proper building orientation, adequate natural ventilation and application of some design elements can provide natural cooling and reduce the energy used for cooling in the buildings. The paper concludes that this will limit the energy demand for cooling and will also result in an adapted architecture to the climatic environment, which will encourage innovation design solutions for building professionals in a hot-dry climate.
\end{abstract}

Keywords: architecture, buildings, climate, cooling, comfort, design, energy, passive, residential, strategies. 


\section{Introduction}

In most developing countries, especially those situated in tropical regions, with a hot dry climate, extreme heat presents special problems in urban areas because of the retention of heat by buildings if ventilation for cooling at night is inadequate (Weihe, [1]). In many of these climatic regions, many of the residential buildings are not suitable for the occupants because a large proportion of the buildings are poorly designed for the climate. In addition, because their economies cannot provide mechanical air conditioning for the majority of their urban housing; the comfort and wellbeing of the occupants therefore depend entirely on the design and construction of the houses.

In Nigeria, designs of apartments in general are not responsive to the requirements of the tropical climate. Residential buildings are designed without giving due importance to the parameters that are responsible for enabling thermal comfort without much dependence on energy use. Dependence on artificial lighting and ventilation is therefore common in all apartments. However, frequent power disruption and load shedding in Nigeria, sometimes over six hours a day, amid hot and dry conditions, have made the life of urban dwellers miserable. As the load-shedding situation continues to worsen, the excessive heat drives people to use more electricity at their homes and offices. The situation becomes worse during the peak dry season from mid March to early May when the ambient temperature becomes very high. During this period, the demand for electricity use goes up to its highest level because of hot weather, as well as a huge need for cooling energy. Because of the increase in energy demand and with its inadequate supply, buildings without active climatization will engender a poor indoor climate, which leads to fatigue, health risks and inefficiency. It is against this background that this study is designed to describe the passive design approach for residential buildings in the hot climate of Nigeria.

\section{Methods}

\subsection{Description of the study area}

Bauchi is located is the north-eastern part of Nigeria at latitude $10^{\circ} 17^{\prime} \mathrm{N}$ and longitude $9^{\circ} 49^{\prime} \mathrm{E}$. The climate is characterized by high temperatures and low humidity in the dry season. The diurnal temperature varies from an average daily maximum of $31.6^{\circ} \mathrm{C}$ to a daily minimum of $13.1^{\circ} \mathrm{C}$. The mean relative humidity is highest in August (66.5\%) and lowest in February (16.5\%). The mean annual rainfall ranges between $800-900 \mathrm{~mm}$ per annum in the southern part and only $700 \mathrm{~mm}$ per annum in the extreme north. The dry season occurs between September and May, while the rainy season is between May and September. The hottest month in Bauchi is April with $40.5^{\circ} \mathrm{C}$, while the coldest months are December and January, with $6.11^{\circ} \mathrm{C}$ and $7.22^{\circ} \mathrm{C}$ respectively. 


\subsection{Method of investigation}

100 urban residences in Bauchi were taken as objects and questionnaire surveys and field measurements on the nature of residential thermal environment were conducted from February-May 2009.

\subsection{Outline of survey}

100 households were the objects for questionnaire survey. Temperature, relative humidity and air velocity measurements were taken. Each household was given questionnaires depending on the number of adults (i.e.16years old above) in the family, 3 liquid crystal thermometers were hung onto the wall at a height of $1.2 \mathrm{~m}$, one for the living room, bedroom and the other for outside under a shaded wall, together with a wet and dry bulb hygrometer. Residents were required to fill the questionnaires while the research personnel record the environmental measurement thrice in a day (7-10am, 12-3pm, and 5-8pm). The contents of the questionnaires mainly include resident's demographic and socio economics characteristics, building characteristics, thermal comfort perception of the living spaces etc.

\subsection{Outcome of investigation}

Cement sandcrete structure plays an important role in the building enclosure with the proportion of $48 \%$, while $20 \%$ of the buildings are built with mud bricks and another $15 \%$ with stone structures, $6 \%$ with burnt clay bricks and compressed earth bricks while just $5 \%$ are built of thatch. The mean size of sleeping room per-household floor areas is from $10.28 \mathrm{~m}^{2}$ while the average room height is $2.7 \mathrm{~m}$. The average window area is $0.89 \mathrm{~m}^{2}$.From the environmental measurement carried out, the temperature measurements in the buildings shows that the conditions are bad since the indoor temperature rises to extremely high value of $37^{\circ} \mathrm{C}$ in the afternoon (figs 1,2 ).

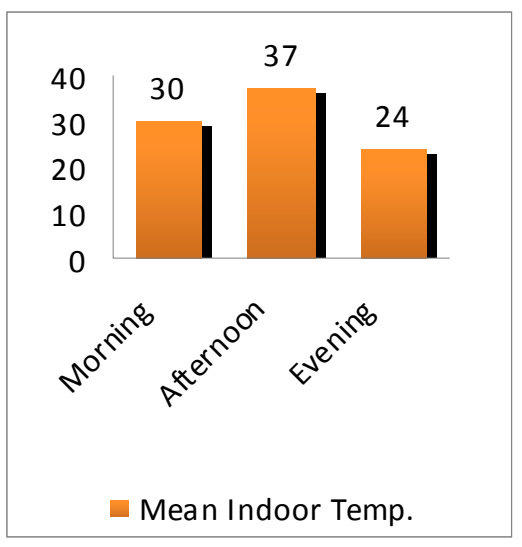

Figure 1: Mean indoor temperature.



Figure 2: Mean outdoor temperature. 


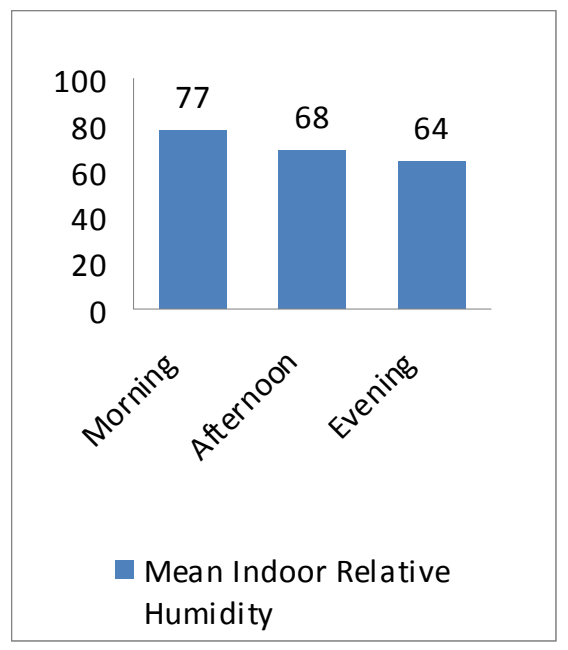

Figure 3.

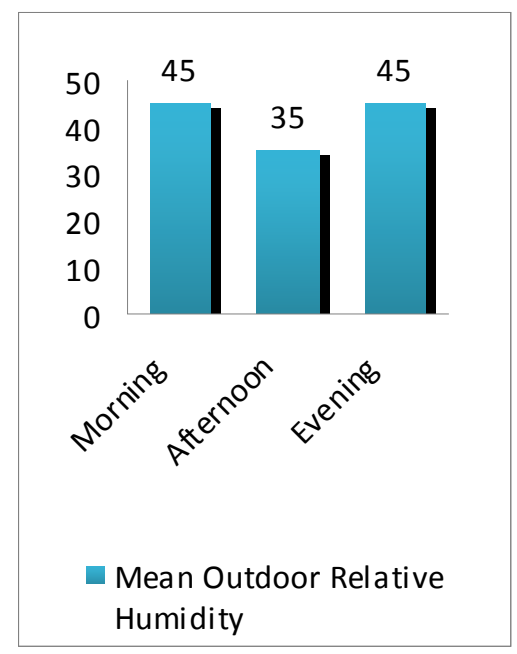

Figure 4.



Figure 5: Thermal comfort vote.

The mean outdoor relative humidity is very much lower compared to that of the inside especially in the afternoon as a result of fluctuations in air temperature (figs 3, 4).

Further investigations shows that the mean indoor air velocity in the day (i.e.morning $(0.12 \mathrm{~m} / \mathrm{s})$, afternoon $(0.11 \mathrm{~m} / \mathrm{s})$ and evening $(0.12 \mathrm{~m} / \mathrm{s})$ is very low hence lead to much dependence on mechanical cooling for comfort. A large portion of the occupants of residences find their thermal environment too warm $(57 \%)$, much too warm $(20 \%)$, comfortable warm $(13 \%)$, and comfortably neutral (2\%) (fig 6). The thermal preference of the occupants of the residences shows the need for indoor cooling of the building for occupants comfort. Greater percentage $(88 \%)$ of the occupants prefers a cooler indoor even though they rely mainly on natural ventilation through the use of window (figs 5,6). 




Figure 6: $\quad$ Preference thermal comfort vote.

\section{The need and benefits of passive design approach in residential buildings}

The global trend in the design and construction of buildings is that of using passive and low -energy strategies to achieve environmental quality especially in hot-dry climate. The hot-dry climate poses environmental challenges of high temperature and this extreme temperature has to be catered for at the design stage to avoid absolute dependence on active energy systems for indoor comfort. In Nigeria, where power supply is epileptic and erratic, most residential buildings depend on energy excessively to attain indoor comfort particularly in buildings that are not passively design. When considering economy of use and unavailability of power supply and even the resultant effect in the green house emission it is better to avoid dependence on active energy system for indoor comfort. Likewise, since mechanical indoor comfort provision accounts for a sizeable percentage of energy use in most buildings, definite approach must be adopted to minimise or eliminate the use of active energy. Low-energy building can be achieved through deliberate choice of passive design approach that suit a particular climate for indoor comfort provision and to accomplish this passive design strategies are needed. Passive design is a low energy-intensive method of keeping a building cool by relying on architectural design. Heat avoidance techniques, natural lighting and natural cooling methods are incorporated in the structure to minimise energy consumption while improving the indoor comfort level. The benefits of passive design are obvious; considerable peak load reduction for the utility company, improved comfort, lower utility bills and little additional cost to the builder.

\section{Passive design strategies for hot dry climates}

Well-designed passive buildings maintain the best environment for human habitation while minimizing the cost of energy. The objectives of passive buildings are to improve the comfort levels of the occupants and reduce energy use (electricity, natural gas, etc) for heating, cooling and lighting. According to 
Hyde [2] passive building design is of importance in hot climate because of limitations of conventional energy a source in terms of both cost and availability. It is evident from the above that passive building design is vital for many reasons. Having justified the needs for passive buildings, it is important to focus on the basic design principles that can bring about energy efficiency and improvement of thermal comfort in residential buildings in Nigeria. The following design strategies are considered for application in hot dry climate in Nigeria:

\subsection{Site selection, analysis and planning}

There are many sources of energy available locally within a building site. These include direct and diffuse radiation from the sun, air movement from winds and temperature differences, biomass from vegetation, as well as geothermal and hydro-kinetic sources. The site is a living and working ecosystem (Yeang, [3]) therefore site selection, analysis and planning constitute the first step of passive design strategy. Adoption of environmental criteria in site selection is proportional with success of other stages directly. The most appropriate ecological, economic and physical fit between site, building development and the resulting cultural landscape is a product of sound site analysis and assessment. Hence, a careful site assessment can enable developers to capture the land's potential views, solar access, natural drainage opportunities, natural shading through vegetation, cooling from prevailing wind while minimizing or avoiding damage or disturbance to the site and surrounding areas. Therefore a proper understanding and analysis of the site resources, relationships, and constraints will enable the designers to maximize energy efficiency while conserving and restoring ecological and cultural resources. UNEP [4] warns that improper planning of the site can result in 'heat island effect'.

\subsection{Building orientation}

In Northern Nigeria, proper orientation of most houses are not given due considerations. Properly oriented buildings take advantage of solar radiation and prevailing wind. According to Gut and Ackerknecht [5], the longer axis of the building should lie along east-west direction for minimum solar heat gain by the building envelope. Wong and $\mathrm{Li}$ [6] performed field measurements and computational energy simulations to examine the effectiveness of passive climate control methods such as building orientation in residential buildings of Singapore. Their results state that the best orientation for a building in Singapore with its tropical climate is for the longer axis of the building to lie along eastwest direction. They also conclude that the cooling load for a residential building can be reduced to $8 \%-11 \%$ by following this orientation.

The passive design feature on orienting the longer axis of the building towards east- west direction, as suggested Wong and Li may not always be possible, especially due to actual orientation of the site, that is, when the site itself is longer on the west and east sides. In such a case, the west facade needs more attention because it heats up in the afternoon and important rooms such as 
bedrooms are generally used later during the day when residents return from office. The east side is less problematic as it warm only in the morning when only few households occupy the major rooms.

\subsection{Surface-to-volume ratio}

The volume of space inside a building that needs to be heated or cooled and its relationship with the area of the envelope enclosing the volume affects the thermal performance of the building. This parameter, known as the S/V (surfaceto-volume) ratio, is determined by the building form. For any given building volume, the more compacts the shape, the less wasteful it is in gaining/ losing heat. Hence, in hot, dry, regions and cold climates, buildings are compact in form with a low $\mathrm{S} / \mathrm{V}$ ratio to reduce heat gain and losses respectively. Also, the building form determines the airflow pattern around the building, directly affecting its ventilation. The depth of a building also determines the requirements for artificial lighting - greater more the depth, higher the need for artificial lighting and greater the energy demand of such building.

\subsection{Room orientation and floor plan zoning}

According to Gut and Ackerknecht, the arrangement of rooms depends on their function and according to the time of the day, they are in use. Watson and Labs [7] have claimed that a house can be made more energy efficient if it is planned according to solar orientation and prevailing wind direction. However, they did specify how much energy saving is possible through such planning. Overheating due to solar radiation is the prominent problem in Northern Nigeria especially in Bauchi during the dry season in the daytime. Givoni [8] points out that crossventilation can be used to enable faster cooling and better ventilation. He stresses that building layout which provides good potential for cross-ventilation is more appropriate for developing countries in hot-humid regions where the vast majority of people cannot afford to buy air conditioners. He recommends a spread out building with openable windows to facilitate cross-ventilation. According to Gut and Ackerknecht, bedrooms can be located on the east side where it is coolest in the evening. Rooms which are in use for most times of the day, such as living rooms should be located on the northern side. Stores and other auxiliary spaces should be located on the disadvantaged side, mainly on the western sides. Provided the kitchen is used during morning and midday hours, it can be located on the west side as well. Rooms with high internal heat load, such as kitchens, should be detached from the main rooms. The usual trend for orientation of rooms in residential buildings of Nigeria is to give maximum priority to master bedroom followed by other bedrooms.

\subsection{Building envelope}

Heat enters and leaves a home through the roof, walls, windows and floor. Internal walls, doors and room arrangements affect heat distribution within a home. These elements are collectively referred to as the building envelope. 
Envelope design is the integrated design of building form and materials as a total system to achieve optimum comfort and energy savings. Good envelope design responds to climate and site conditions to optimise the thermal performance. It can lower operating costs, improve comfort and lifestyle and minimise environmental impact. As the main goal in building design of tropical climates is reduction of direct heat gain by radiation through openings and reduction of internal surface temperature, the building should be designed with protected openings and walls (Gut and Ackerknecht [5]). The external walls can be protected by designing the roof so that it extends far beyond the line of walls and has broad overhanging eaves. Cheung et al. [9] had conducted a study to reduce the cooling energy for high-rise apartments through an improved building envelope design. Their study shows that annual cooling has an almost linear relationship to the solar absorptance (amount of solar energy that passes into a material) of the external surfaces. Energy savings were found to be high with lower solar absorptance. A 30\% reduction in solar absorptance can achieve a $12 \%$ saving in annual required cooling energy. They concluded that $12 \%$ saving on cooling energy could be obtained from using white or light colour external wall finishes.

\subsection{Utilizing natural resources as building materials}

Generally materials used in modern buildings obstruct the flow of air, making the use of mechanical ventilation essential. In Nigeria, buildings are usually built with cement blocks but in recent times, the use of local materials is being promoted and a lot of research is being done into its efficiency and sustainability for achieving good indoor climate. In almost all localities, nature has provided us with some good quality materials to build with and some of these materials require little processing or transporting. Some of these materials are renewable resources like trees and straw, and some may be so abundant that their supply seems almost inexhaustible like rocks, clay and sand. One of the beauties of building with local materials is that they seem to fit well with the feeling of the place naturally (Hart and Hart, [10]). Fortunately, most of these materials are readily available in Nigeria but are not used optimally. The issue of indoor temperature and energy use is often dependent on the building materials. Mud brick (adobe) is an extremely valuable building material, useful for both walls and floors. It is composed of between 20 and 30percent clay, with the rest mostly sand. Such soil is common in many areas of Nigeria, though buildings made of adobe are mainly found in the northern part and this has been mostly adopted for economic reasons and for a good indoor temperature due to the extremely high temperature found in the area. Irrespective of where the mud bricks are used, they are often known for their cooling effect. Especially at night, residents can be assured of a good indoor climate without the use of any mechanical effects. A significant development on this material has been the manufacture of cement stabilised compressed earth block. Soils used in these blocks are clay based weathered rock. The blocks are stabilised with as little as $5 \%$ off white cement and compressed to give a mass of $2,200 \mathrm{~kg} / \mathrm{m} 3$ houses built from these blocks have maintained comfort conditions in a wide variety of climatic zones. They 
take maximum advantage of the fact that small changes in mean radiant temperatures have a far greater effect on the comfort of the occupants than similar changes in air temperatures

\subsection{Natural ventilation}

Living in hot climate can quickly become uncomfortable for its inhabitants with the extreme heat that is built up by midday. That is why it is important for the building structure to have effective ventilation and an internal temperature below the outdoor level. Natural ventilation keeps the air moving within the indoor environment and, therefore, keeps the inhabitants cooler even without the use of energy. Wong and Huang [11] made a comparative study on the indoor air quality of naturally ventilated and air-conditioned bedrooms of residential buildings in Singapore. They observed that CO2 levels of bedrooms using air conditioners are consistently higher than those utilizing natural ventilation. Thermal comfort comparison of the air-conditioned bedrooms and naturally ventilated bedrooms indicate that the air-conditioned bedrooms are usually substantially overcooled, resulting in extremely high PPD (Percentage People Dissatisfied). Whereas, in natural ventilated bedrooms, the utilization of fans was sufficient to achieve the required thermal comfort. They also found that occupants utilizing air conditioners exhibited more SBS (sick building syndrome) symptoms than those utilizing natural ventilation. Liping et al. [12] also conclude that natural ventilation is an attractive alternative to reduce the associated problems with air-conditioned buildings because natural ventilation has potential benefits such as reduced operation costs, improved indoor air quality and satisfactory thermal comfort.

\section{Application of design elements for natural cooling in residential buildings}

Some common design elements that directly or indirectly affect thermal comfort conditions and thereby the energy consumption in a building includes:

\subsection{Landscaping, vegetation and greenery}

Landscaping is the most under utilised area of domestic architecture in spite of the fact that it is probably the cheapest and most effective way of improving year round comfort and energy efficiency. In Nigeria, vegetation grows rapidly around and can be use as an architectonic element either vertically or horizontally in the shape of pergolas, screens, vegetated atriums, patios, flower pots, and others, in order to create microclimates and to favour architectural design. Internal and external vegetation could be considered as a potential design element. The idea is to use it as an essential characteristic to reflect the architecture of the area and to produce the benefit of a microclimate that adapts buildings to their immediate environment. The use of vegetation provides shade and freshness almost the whole year. When the buildings in hot climates are surrounded with vegetated screens, a 
natural freshness that isolates the building from sun rays is achieved. Raeissi and Taheri [13] acknowledge the beneficial effects of trees and vegetation. They state that plantation of trees can result in energy saving, reduction of noise and pollution, modification of temperatures and relative humidity and psychological benefits on humans. Their study on proper tree plantation for energy saving concludes that the cooling loads of a house can be reduced by $10 \%-40 \%$ by appropriate tree plantation. Even though appropriate tree plantation can bring significant amount of energy savings, this design principle can only be applicable in buildings of Nigeria if adequate space is left open either as a set back area or as designated green space within the residential environment.

\subsection{Enclosed courtyard between buildings}

Another common natural ventilation and thus cooling technique is the use of atria and courtyards. Courtyards can reduce the cooling energy needs of residential buildings in a very significant way especially if carefully designed.

\subsection{Introduction of fountain between buildings for evaporative cooling}

Evaporative cooling lowers indoor air temperature by evaporating water. It is effective in hot-dry climate where the atmospheric humidity is low. In evaporative cooling, the sensible heat of air is used to evaporate water, thereby cooling the air, which in turn cools the living space of the building. Increase in contact between water and air increases rate of evaporation. The presence of a water body such as a pond, lake, sea etc. near the building or a fountain in a courtyard can provide a cooling effect. This process is called adiabatic with no heat being gained or lost (fig 7).

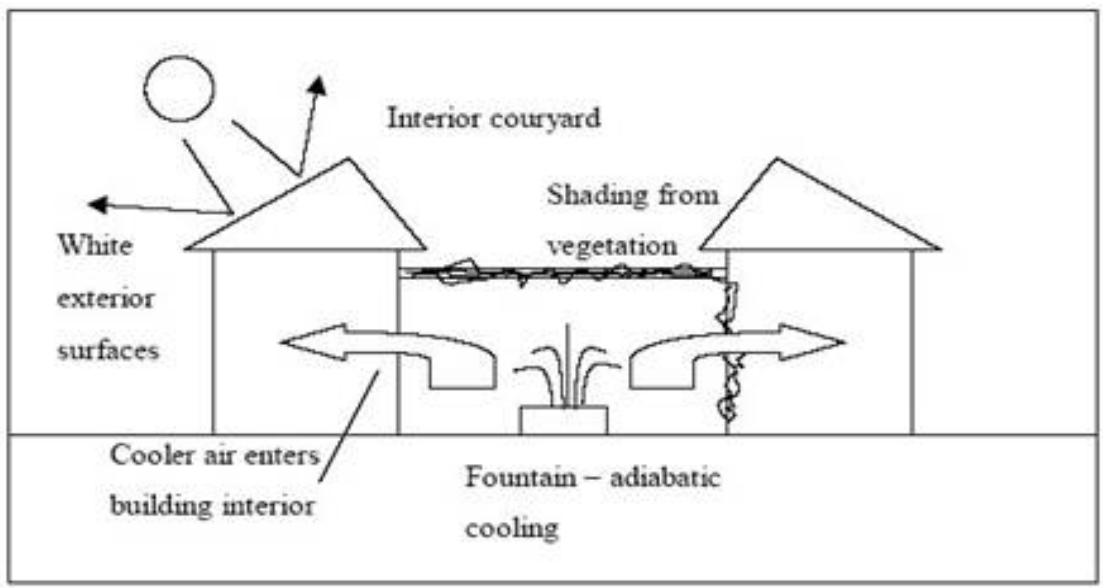

Figure 7: Evaporative cooling through the application of a fountain between buildings. 


\section{Conclusions}

Buildings will cause thermal discomfort if an effective strategy is not adopted to reduce the extra heat going into it. Out of the numerous passive design strategies that have been adopted by others in different climates, only those strategies discussed in this study have been chosen that can meet the purpose of this study and can be applied in the context of hot dry climate of Nigeria. The strategies selected pertain only to possible energy savings and enhancing low energy architecture in tropical climate. By adopting the above mentioned design strategies this will limit the energy demand for cooling and will also result to an adapted architecture to the climatic environment which will encourage innovation design solutions for building professionals in hot-dry climate.

\section{References}

[1] Weihe, W.H. Life expectancy in tropical climates and urbanization. World Climate Technical Conference. Geneva, World Meteorological Organization, pp. 313-353(WMO No.652), 1985.

[2] Hyde, R. Climate Responsive Design. E and FN Spon. London, U.K., 2000.

[3] Yeang, K. Designing with Nature, Mcgraw Hill, USA, 1995.

[4] UNEP. Eco-housing Guidelines for Tropical Regions. Bangkok: United Nations Environment Programme Regional Resource Centre for Asia and the Pacific, 2006.

[5] Gut, P. \& Ackerknecht, D. Climate Responsive Building: Appropriate Building Construction in Tropical and Subtropical Regions. Switzerland: SKAT,1993

[6] Wong, N.H. \& Li, S. A Study of the Effectiveness of Passive Climate Control in Naturally Ventilated Residential Buildings in Singapore. Building and Environment, 42 (3): 1395-1405, 2007.

[7] Watson, D. \& Labs, K. Climatic Building Design: Energy-Efficient Building Principles and Practice. New York: McGraw-Hill, 1983.

[8] Givoni, B. Climate Considerations in Building and Urban Design. New York: Van Nostrand Reinhold, 1998.

[9] Cheung, C.K., Fuller, R.J. \& Luther, M.B. Energy-Efficient Envelope Design for High-Rise Apartments. Energy and Buildings, 37 (1): 37-48, 2005

[10] Hart, K., and Hart, R. Keep Your Cool. Retrieved on 2005-06-09 from http://www.greenhomebuilding.com/recyclematerials.htm 2005

[11] Wong, N.K. \& Huang, B. Comparative Study of the Indoor Air Quality of Naturally Ventilated and Air-Conditioned Bedrooms of Residential Buildings in Singapore. Building and Environment, 39 (9): 1115-1123, 2004.

[12] Liping, W., Hien, W.N \& Shuo, L. Facade Design Optimization for Naturally Ventilated Residential Buildings in Singapore. Energy and Buildings, 39 (8): 954-961, 2007.

[13] Raeissi, S. \& Taheri, M. Energy Saving by Proper Tree Plantation. Building and Environment, 34(1999): 565-570, 1999. 